\title{
Watch the Birdie: The Star Economy, Social Media and the Celebrity Group Selfie
}

\author{
ELLEN WRIGHT University of Lincoln
}

\begin{abstract}
This work will explore some of the broader implications of celebrity group selfies, through the example of Ellen DeGeneres' star-studded group shot, taken during the 2014 Academy Awards ceremony, Joan Collins' 2014 Prince's Trust Award selfie, just days after, and Collins' subsequent 'view from the other side' tweet; exploring notions of authenticity, performance, intimacy, self-promotion, public visibility, identification, imitation, vicarious consumption and audience participation.
\end{abstract}

Engaging with existing work upon celebrity tweeters, Twitter and other online fandom, photographic theory, star studies and, in particular, Bourdieu's theories surrounding cultural capital, taste formation, and cultural distinctions, this work not only explores some of the reasons behind the frequently negative judgements of celebrity group selfies, but also seeks to identify some of the very real social functions and more personal gratifications, both for celebrity and fan, that the celebrity group selfie, as a communication and a selfpromotional tool, may actually satisfy.

More specifically, it is this paper's contention that selfies offer an ostensibly unmediated, accessible and virtually instantaneous means of articulating and disseminating a coherent, identifiable, aspirational (yet bizarrely, also, seemingly 'ordinary') and eminently marketable star image, via a popular and up-to-date medium. With celebrity group selfies this is also the case, but here the photographer subject presents an image of themselves to the world, in relation to a specific group of peers (who themselves also function as signifiers and commodities); perpetuating the notion of a pantheon of star 'gods' and the myth of a coherent celebrity community; reinforcing the divide between 'famouses' and 'normals' and participants and observers; prompting an exponential rise in fan/public interest as more stars enter the equation and allowing the celebrity participants within the image to either borrow some of the greater 'worth', 'status' or cultural capital of other, more eminent, celebrity subjects also pictured or alternatively, lend their superior cultural capital to less successful celebrities within the image.

As such, this work seeks to move beyond a hasty dismissal of such images, their subjects, and their audiences and instead, hypothesise a coherent set of reasons why the mostphotographed individuals on the planet (not just film stars, but heads of state and religious leaders) might feasibly choose to create, appear in and/or disseminate such images (or, indeed, decline to participate as did Prince Charles in Joan Collins' group shot) and why the public may find these images of such interest.

\section{KEYWORDS}

stardom, celebrity group selfie, cultural capital, audiences, twitter 
Comedienne and Oscars emcee Ellen DeGeneres' star-studded group shot, taken on her mobile phone during the 2014 Academy Awards ceremony, was reTweeted over 3 million times and caused the social networking site Twitter to crash momentarily. The image was described by the Telegraph as 'the sensation of the Oscars', 'the most famous 'selfie' in the world' (Wallop 2014) and by the Daily Mail as 'the epic selfie that broke Twitter'(Fahy and Flint 2014). According to Sky News, 'within an hour the picture had received 870,000 reTweets and had been "favourited" 210,000 times'; shortly after her Tweet, DeGeneres reported to her awards ceremony audience that "We crashed and broke Twitter. We have made history." The volume of traffic generated by the image was such that Twitter service was disrupted for more than 20 minutes. By the following day 'the image had received 2.4 million reTweets and 1.1 million favourites' (Sky News 2014). But just days later, when Hollywood veteran Joan Collins posted her own group shot from the red carpet at the 2014 Prince's Trust Awards in London, her image received a mere 59 reTweets over the next two days (Davidson and Williams 2014) ${ }^{1}$ and was termed by Jenn Selby (2014) of the Independent as 'cringe-worthy' and 'the lamest celebrity selfie of all time'.

The reception of and reaction to these two images indicates some potential winners and losers in what Chris Rojek terms the 'celebrity status economy' (Rojek 2001, 74). As such, an exploration is due of the politics at play and the social functions and personal gratifications offered by the creation and dissemination of celebrity group selfies and of some of the reasons behind the (primarily negative) reactions to the form and the circumstances of their production. Although selfies and group selfies (celebrity and otherwise) are more commonly dismissed as vacuous, narcissistic and self-promoting, the fact that they continue to be taken and reTweeted within the larger Twittersphere and are intermittently discussed within the broader media suggests that they clearly hold an appeal and a function, at least for some. This essay sets out to explore these issues, helping to fill the current gap in knowledge about this photographic mode and its uses amongst celebrities and the public.

The celebrity group selfie is a variant upon the photographic form of the selfie, but with multiple participants who either already have or, through their appearance in the celebrity group selfie, come to experience some degree of celebrity status.

The Oscars group selfie was not the first time the celebrity group selfie had become newsworthy. Just a month after the word 'selfie' was named 'Word of the Year' by the Oxford English Dictionary, Danish Prime Minister Helle Thorning-Schmidt took a group shot with a grinning Barrak Obama and David Cameron at Nelson Mandela's funeral and caused a media sensation. For taking and posing for this photograph, Thorning-Schmidt, Obama and Cameron were accused of conduct unbecoming of heads of state. ${ }^{2}$ Perversely, common media consensus was that this was a momentary, but deeply inappropriate breach of etiquette, despite the tendency across many cultures to use the funerary ritual as a group photo opportunity and a means to reaffirm or create bonds between those in attendance ${ }^{3}$ and in spite

1 A Daily Mail article on the $14^{\text {th }}$ of March observed that 'Joan has currently only had 59 retweets' (Davidson and Williams 2014)

2 Presumably this is why, when asked, Prince Charles declined to be included in Joan Collins' group selfie at the Princes Trust Awards.

3 Susan Sontag discusses taking and posing for photographs as a 'social rite' $(1977,8)$, discussing the 'acquisitive mentality implicit in all picture-taking' (1977, 109). Similarly, Bourdieu identifies one of five key 
of the thousands of 'acceptable' photographs also shot at this particular event by media professionals (including the shot of the unsuspecting Thorning-Schmidt party as they took their infamous snap, which subsequently went viral). ${ }^{4}$

The Oscars group selfie also generated controversy. Amongst a sea of media articles about the image itself and the wider social and media phenomena of the celebrity selfie and celebrity group selfie, complaints were made that DeGeneres undertook a shamelessly commercial act (the image was taken on a Samsung phone, Samsung Electronic Co. having paid a reported $\$ 20 \mathrm{~m}$ to sponsor the Oscars broadcast), ${ }^{5}$ the image was denigrated for being contrived, despite its seemingly spontaneous appearance (on her chat show, Ellen, DeGeneres appears in footage of Oscars rehearsals discussing how to break the reTweet record with her production team, before practicing propositioning celebrities for selfies with her smart phone) and it was also claimed that the image (and its re-Tweets), were indicative of a broader and self-evident social malaise.

As Susan Bright (Bright 2005, 8) notes, the photograph's mechanically produced origins, the ease with which photography can be mass produced, its subsequent links with commerce and, perhaps most importantly in this instance, the perceived lack of 'artistic' skill required to generate such images has meant that historically photography has often been unfavourably perceived as the poor relative of painting; the 'servant to art', (Baudelaire 1980, 88) ${ }^{6}$ the 'scribe not [the] poet' (Sontag 1977, 88) and a lowbrow medium for the lowest common denominator. Kodak's well-intentioned advertising slogan: 'You press the button, we do the rest', used in the late $19^{\text {th }}$ century, to promote, to an uncertain public, the first 'point-andshoot' cameras and photographic development services, typifies the assumed lack of skill which is, to this day, still commonly associated with non-professional photography. These unfavorable associations have been intensified by the relatively recent move away from the alchemical complexities of chemical photography, towards digital photography and the proliferation of more technically complex, higher specification yet increasingly user-friendly cameras, self-focusing camera phones and accessible social media upon which upload, store and display such images. The selfie epitomises that frequent association with simplicity, disposability and the lowbrow. Like most snapshot photography, its emphasis is upon capturing experience over technically-skilled execution.

motivations for taking photographs as 'protection against time' and against the loss that the passing of that time inevitably incurs $(1996,14)$.

$4 \quad$ As Smith (2014) notes 'While professionals with expensive equipment are apparently fine to photograph the array of well-known faces in the crowd, some of those same individuals taking the means of photographic reproduction into their own hands, and phones, somehow is not. On one level this is the selfimportant hypocrisy of the wedding photographer, who doesn't want anyone else taking photos at the wedding, a turf war, a claim for demarcation. But at another level this is entirely about technology, that the photograph was taken on a phone, held by one of the subjects, coupled with the disparaging current rhetoric around the phenomenon of the 'selfie' is key.'

Christopher Palmieri of Bloomberg Business Week listed Twitter Inc and Samsung Electronic Co 'amongst the list of winners at last night's Oscars ceremony for their product placement coups'. Bloomberg Business Week 'DeGeneres Selfie Makes Twitter an Oscar Winner With Samsung' [online] March 3, 2014. Available at http://www.businessweek.com/news/2014-03-02/degeneres-s-oscars-selfie-crashes-twitter-withrecord-retweets.html Accessed December 10, 2014

$6 \quad$ And the 'secretary or record keeper of whomsoever needs absolute material accuracy' (Baudelaire 1980,88) 
Criticisms of the Oscars group selfie for its commercialism and contrivance also carry a potentially disingenuous implication that because the image-taking process was a publicity stunt (not only for Samsung, but also for the Ellen Show and for DeGeneres herself, as the image was Tweeted from her personal account, @TheEllenShow) what must therefore have resulted is inauthentic. The poor resolution, the blurring, the distorted faces and the poor composition are all tropes commonly associated with the selfie and with amateur, snapshot photography more generally. These elements draw the spectator's attention to the lack of 'good' (i.e. invisible) photographic practice, making the act and the moment of photographic intervention; the contrivance, even the inferred element of performance and of scrutiny more apparent.

But these same elements can, paradoxically, also connote authenticity. In her forum article on the ironic selfie and transmedia celebrity self-promotion, Beccy Collings observes that 'Selfies are a boundary-blurring medium... being a mixture of private/public or authentic/inauthentic' (Collings 2014, 512) and that:

While these photographs typically present themselves as providing a privileged glimpse of the backstage/private celebrity self, making this seem authentic often means drawing upon aspects of the frontstage/public persona - catering to viewer expectations, in effect. (Collings 2014, 513)

In the selfie and the celebrity group selfie, as in much self-portraiture, it is a different kind of truth: an indexical truth that is revealed. This truth hinges upon effectively conveying or allowing the audience to gain a sense of the individual photographed and, in the case of celebrity or star representations, of the 'star persona' (Dyer, 2007). Celebrity selfies and celebrity group selfies therefore reveal something seemingly authentic about that persona, bringing to mind Richard Dyer's discussion of the simultaneous ordinariness, and extraordinariness of stars, this being whereby stars 'live more expensively than the rest of us, but are not essentially transformed by this' $(2007,43)$. In fact, the 'wealth and success of the stars can be seen as serving to isolate certain human qualities' (Dyer 2007, 43).

As signifiers within a celebrity group selfie, candid image, or in more overtly contrived photographic representation, the star or celebrity is a signifier who suggests a range of significations or meanings. As Hamilton and Hewer (2010) note, in terms of 'investing' in particular celebrities 'fans select stars that offer "opportunities to make meanings of their social identities and social experiences that are self-interested and functional"' (Fiske 1992, 35). Celebrity products (products featuring celebrities) are thus used as a means for organising identity (Hamilton and Hewer 2010, 280). Star personas are Hollywood's stockin-trade and extra-textual materials such as pin-ups or candid 'behind the scenes' photography have always helped to 'sell' stars by highlighting a star's specific marketable elements: the broader personality traits, ideas, associations and appeals or as Rachel Moseley (2002) terms these 'resonances' (the process of 'back and forth' (Moseley 2002, 8) in terms of meaning between 'star' or 'star text' and fan) that coalesce to form a coherent star persona and ultimately what Dyer terms the 'total star text' (Dyer 1986, 17) (the star as represented across multiple media which cumulatively forms a star's complete image or 'star persona'). As Lueck's (2012) study of the parasocial advertising of reality TV star and celebrity Tweeter Kim Kardashian demonstrates, modes of communication such as the selfie form part of a highly effective means through which a coherent, identifiable and marketable star image can 
be both constructed and disseminated via a popular, accessible and up-to-date medium with considerable cultural cachet.

In the celebrity group selfie, the photographer subject appears not only to be presenting an intimate, authentic and thus identifiable image of themselves to the world, but they are represented in relation to a specific group of others, each with their own attendant 'meanings'. In this arrangement stars each bring their own cultural capital or celebrity 'worth' to the image and this is augmented by what is, essentially a cumulative capital - an amalgamation of the collective 'worths' of all the participants - which emerges through the star participants each either borrowing capital from, or lending capital to their fellow participants. The 'worth' of the celebrity group therefore becomes greater than the sum of the individual participants' individual status value. Appearing amongst one's celebrity peers in a celebrity group selfie then, offers a means of affirming one's place in the star firmament, increasing and/or demonstrating one's social and cultural capital ${ }^{7}$, and in turn, one's economic value within the celebrity industry by 'borrowing' cultural capital from your fellow celebrity subjects (hence Liza Minnelli and Jared Leto's equally frantic bids to be included in the Oscars image, as I'll discuss shortly).

As Rojek notes, in his study of celebrity, events such as the Academy Awards are one of a 'variety of ceremonies of ascent [...] [which are intended to] symbolise honorific status'(Rojek 2001, 75) ${ }^{8}$ and are deliberately designed as ritual opportunities for stars and celebrities to increase or consolidate their social and cultural capital and, in turn, their economic value. These events function as a platform from which celebrities are expected to display their wealth, popularity and/or their attractiveness, these being some of the key traits that mark them as exceptional or extraordinary individuals and therefore worthy of fame. Photography (particularly the red carpet opportunity) is crucial to this ritual. Here the celebrity must convincingly play and be seen to play the part of the popular, confident, stylish and enviable star.

For celebrities who take and tweet selfies, these events also offer a further opportunity to not only increase their public visibility, with an exclusive 'behind-the-scenes' self-portrait, but also to demonstrate their techno savvy and their engagement with, and ability to set, current media trends. In the case of the 2014 Oscars, the huge array of celebrity selfies taken and Tweeted before, during and after the ceremony bear testament to the clear communicational and promotional benefits and satisfactions offered by the selfie. However, as a mode of communication, the Tweeted selfie can backfire. Presumably part of why Joan Collins' group selfie is labelled as 'cringe-worthy' is partially because at 80 , she is not the anticipated (or possibly desired) target audience for Twitter, nor is she the anticipated (or possibly desired)

\footnotetext{
7 In terms of differences between what Bourdieu terms as social and cultural capital, a subject's social capital is the qualities or assets at the disposal of the subject, but largely external to that subject, namely relationships and networks of influence and support. Alternatively, cultural capital concerns qualities which are possessed by the subject, such as particular skills or specific knowledge which could confer status or advantage to said subject. For a more detailed discussion of these terms see Bourdieu, P. (1986) 'The Forms of Capital', in Richardson J. G (ed), Handbook for Theory and Research for the Sociology of Education, Santa Barbara: Greenwood Publishing Group pp.241-258

Rojek comments upon the secular nature of modern, western culture and the subsequent tendency within the media, when representing celebrity, to 'draw on myths and rites of religious ascent and descent' $(2001,74)$.
} 
producer of such images, but also because of the relatively lower celebrity status of the stars who feature alongside her in her image in comparison to those who feature in the Oscars group shot.

Audiences are encouraged to value Hollywood stars and celebrities as desirable products ${ }^{9}$ whose monetary worth, social media currency or box office draw is an index of that stars' celebrity status, in the vein of ' 1000 s of people can't be wrong.' In terms of the draw this offers to audiences, the common understanding in the popular media (who generally seek to harness these audiences for their own promotional ends) is that the only thing more fascinating or desirable than a picture of a popular film star on the red carpet, is two popular film stars on the red carpet. There is an ever increasing rise in the draw or excitement generated by an image, as more and more stars are added to the equation. In terms of a historical example, MGM's promotional tagline, whilst at the height of its powers as a vertically integrated studio, conflated abundance with excellence by claiming they had on their roster 'More stars than the heavens'.

On Twitter, the celebrity group selfie then, is very practicably greater than the sum of its parts. If each star participant is individually worth several million dollars to studios, networks or sponsors, or in instances wherein success is measured by volume of internet traffic, has several thousand Twitter followers, by implication, the collective worth of a number of stars is exponential. This equation is epitomised in the anchoring comment Tweeted alongside DeGeneres' group selfie: 'If only Bradley's arm was longer. Best photo ever. \#oscars' (@ TheEllenShow 2014). The intimation here being the longer the arm the more stars could be included in the image and, by implication, the greater the 'worth' of the image by dint of the increased cumulative capital.

In the Oscars group selfie the dinner jackets and bow ties, ostentatious jewellery, off-theshoulder dresses and immaculately coiffured hair, suggests a sense of occasion and signifies material wealth and an abundance of leisure time in which to achieve such polished appearances. The subjects' smiles and seemingly direct eye-contact, Angelina Jolie's friendly wave, Julia Robert's hysterical laughter, Kevin Spacey's bemused expression and the disorganised way in which they have hastily assembled, suggests a convivial atmosphere. Furthermore, the skewed angle; the photographer's failure to correctly frame and fully include all the subjects in the shot (as per the rules of good photographic practice) draws attention to the process of production, generating a candid, spontaneous and informal tone; intimating more intimate and unmediated access to the stars pictured.

The star subjects exhibit a range of recognisably spontaneous reactions, whilst appearing in a basic social situation (the taking of a spontaneous, amateur group shot to commemorate a social event) with which their audience can readily identify. This impression of spontaneity and the way in which this image invites audience identification, is enhanced further still by the prominence within the image of Peter Nyong'o (on the far right of the picture), whose only claim to celebrity fame is being the brother of Lupita Nyong'o, who ironically, finds herself at the very rear of the shot. Here 'one of us' finds himself part of the photographic

9 For example, Rojek notes that 'celebrities are commodities in the sense that consumers desire to possess them' $(2001,15)$. 
event of the year and temporarily (and in a sense, fraudulently) part of the celebrity firmament through a process of 'fame by association' (Bull 2010, 177).

Participation and association are also key when considering the consumers of this image and potential reasons why it became the most reTweeted image ever. As with the consumption of all of Hollywood's products; stars, films and other associated goods, consumption functions as a means of vicarious participation and the Oscars group selfie was no exception. Such an image could be a way of learning or seeing more about a star, in line with Susan Sontag's statement that:

to photograph is to appropriate the thing photographed. It means putting one's self in relation to the world that feels like knowledge - and therefore, like power (Sontag 1977, 4).

Working with Schickel's observation that 'audiences feel that they personally know these famous personalities and often develop an "illusion of intimacy" with them' (Schickel 1985, 29), Lueck discusses Horton and Wohl's definition of 'parasocial interaction': a "simulacrum of conversational give and take" between senders and receivers of mass media messages' highlighting that 'this type of social interaction is one-sided and mediated' (Lueck $2012,4)$. In terms of 'fanish' or 'tribal' ${ }^{10}$ behaviour then, viewing, reTweeting and discussing such an image can be a way of vicariously associating one's self with the imagined world or experience of a celebrity, whilst demonstrating one's fandom or affinity for that particular celebrity to one's peers or even, potentially, to the star themselves (as the celebrity may see the reTweets or comments).

Within the 'update culture' (Murthy 2013, unpaginated) of Twitter, such an image simultaneously operates as a means for audiences to demonstrate their own cultural and social awareness/capital and technological aptitude amongst their online peers by demonstrating how up-to-date they are, in terms of cultural developments, whilst simultaneously satisfying the need to participate and be seen to be participating in debates surrounding these developments, prompted, in part, by the recently-termed phenomenon of 'FOMO' ('Fear of Missing Out').

As Twitter is an 'event-driven medium' (Murthy 2013, unpaginated) reTweets of and Tweets about prominent celebrity group selfies, as with any prominent or influential Tweet or Tweeted image, function as an extension of the 'event' forming an event in itself. Audience members who reTweet and comment upon such developments, through the use of their phone/computer and the social media site, vicariously become part of 'the story', part of 'the event', even, in the case of the record-breaking Oscars group selfie, part of 'history'.

It follows then, that audiences' negative responses also form a key element within the broader narrative surrounding these images. One tweet made directly to Collins' account regarding the Princes' Trust group selfie somewhat unkindly refers to her group selfie as the 'Aldi version' (@juicyjohn, 2014) of the Oscars group shot, making reference to the budget supermarket chain and by implication suggesting the lowbrow, poor quality status of Collins'

$10 \quad$ See Hamilton and Hewer (2010). 
image and the comparatively low levels of cultural capital possessed by the celebrities within it. Equally, another tweet joked 'I think we may have reached 'peak selfie' (@dudleycruse 2014). The implication here being an oversaturation of selfies and selfie discourse in the popular media and that in her eagerness to be 'current', to display her media and technological know-how and to increase her cultural capital, the octogenarian celebrity had possibly 'jumped the shark'; inadvertently emphasising her age (in an industry obsessed with youth) and her potentially out-dated, moribund state of celebrity. Hence Jenn Selby's 'cringeworthy' comment made in the Independent.

Considering other losers in the celebrity selfie stakes, actress Liza Minnelli also met with ridicule in popular and social media for her attempted participation, but ultimate exclusion from the Oscars group selfie. Images taken and Tweeted by fellow audience members, such as Harry Clayton Wright's: 'POOR LIZA. It's just not her night. \#Oscars2014' (@HClaytonWright 2014) reveal Minnelli leaning across a row of fixed seating, grabbing at Julia Roberts' arm, in an attempt to be acknowledged and included within the shot. In line with Rojek's notion of descendant celebrity $(2001,78)$, much of the discourse surrounding the Oscars group selfie and the circumstances of its production alludes, either viciously, jokingly or sympathetically, to Minnelli's desire to be in the shot. A common implication here being that this act was indicative of the star's broader yearning for visibility and for celebrity, drawing upon an established star narrative which historically features tropes of victimhood, vulnerability and emotional dependency; stemming primarily from her own persona, but also potentially from her mother, Judy Garland's, troubled star narrative.

It is notable that the actor and musician Jared Leto isn't discussed in the media as being desperate or fame hungry, despite his equally frantic (but ultimately successful) bid to 'photobomb' the Oscars group shot, (leaving his seat and dashing across the theatre auditorium to be in the photograph). ${ }^{11}$ This could well be because of his similarity, in terms of age, to the demographic most likely to be Tweeting about, reading Tweets about and reTweeting Tweets about the Oscars, but is most probably because of his current cultural cachet, as he went on, that evening, to win the Oscar for Best Supporting Actor, thus instantly increasing his star 'stock'.

It is also worth considering professional shots of the Oscars and the Princes' Trust group selfies being taken. In the documentary tradition, and as with the professional shot of the Thorning-Schmidt group selfie, these images present the public with another layer of 'truth' by capturing the actual moment of the celebrity group selfie's creation, purporting to offer the spectator greater access by offering 'another angle' and revealing elements that may have inadvertently, or deliberately been excluded from the image, such as Liza Minnelli in the Oscars group selfie or a handful of celebrities who posed for the Princes' Trust group selfie.

Shortly after Tweeting the Princes' Trust group selfie, Collins also Tweeted one such professional photograph with the caption 'what it looked like from the other side!' However, taking this comment literally, this second image is actually shot from a similar angle to the

11 In an interview for the Ellen show, the day after the ceremony, DeGeneres discussed the taking of the Oscars group image with Leto, fondly remarking: 'I loved that you ran from the other side [of the theatre auditorium] and only your eye got in... I could hear, as the picture was being taken, I could hear you running, going 'I'm in on this!' Ellen show, aired March 2014 
group selfie itself so the perspective offered is very similar. Presumably what is meant by a view 'from the other side' is a view from across the invisible, but ever-present boundary between celebrity gods and public mortals; a shot that that purports to reveal, to offer privileged access and expose the machinery of celebrity but which actually necessarily reaffirms both the public's role as distant spectators rather than participants, bringing to mind Chris Rojek's observation that:

Celebrity status always implies a split between a private self and a public self.... The public presentation of self is always a staged activity, in which the human actor presents a 'front' or 'face' to others while keeping a significant portion of the self in reserve (Rojek 2001, 11)

and Stephen Gundle's observation regarding glamour:

Distance is a necessary factor in the maintenance of glamour. It serves to conceal or disguise the aspects of a person's being that are not glamorous. We generally see the glamorous person the way they want us to see them... Glamour is experienced at one remove and sometimes, in the age of the media, at several removes... It belongs to the realm of representation and not knowledge (Gundle 2009, 14).

Twitter therefore functions here as a necessarily complex and obfuscatory bridging mechanism between what Grace Dent calls 'normals' and 'famouses' (Dent 2011, 179). Whilst purporting to offer audiences privileged access: to become part of the event or a member of the celebrity entourage, the Oscars group selfie, as with other celebrity group selfies, must still reinforce the notion of privilege and of a pantheon of gods. So it is reinforced to 'normals', that their primary means of participation within this equation is to observe, but they are still offered a conciliatory means of vicarious activity, in the form of the follow, the Tweet, and the reTweet and are therefore still given a stake in the 'event'.

In 'the age of mass celebrity': an age whereby 'there is $[\ldots]$ a common desire $[\ldots]$ to be famous. This is not fame as a result of having achieved success in a profession, but the achievement of fame as connoting success in itself' (Bull 2010,178) media platforms such as Twitter accounts offer celebrities a useful means through which to construct an appealing, coherent, seemingly authentic and marketable persona, exploiting the parasocial nature of the medium to generate a sense of intimacy and effectively, brand loyalty. As such, the medium affords audiences the opportunity to engage both with that celebrity and with others about that celebrity.

Of course, there are a multitude of differing motivations for taking selfies and a number of resonances offered to audiences by these images. According to Bourdieu, in his study, primarily of amateur photography clubs and professional photographers during the 1960s, 'the fact of taking photographs, keeping them, or looking at them may bring satisfactions in any of five areas, protection against time, communication with others and the expression of feelings, self-realisation, social prestige, distraction or escape' (Bourdieu 1996, 14).

Whilst these five uses were identified well in advance of the age of social media, three uses in particular; 'communication with others'; 'self-realisation'; and 'social prestige' still remain particularly relevant here as they prompt a number of useful considerations regarding 
celebrity Tweeters, audiences, social photography and social media, within an altered circumstance whereby capital isn't measured or accumulated by or through photographic ability, but instead through the ability to accumulate audiences and provoke Twitter responses with particular images and Tweets. In terms of 'self-realisation' Bourdieu observes that photographic activity:

gives photographers the means of 'realising' themselves either by making them feel their own 'power' by magical appropriation or by the recreation, either glorified or caricatured, of the object represented, giving them the opportunity to 'feel their emotions more intensely' or allowing them to express an artistic intention or demonstrate their technical mastery (Bourdieu 1996,14).

However, in the age of social media, the 'self-realising' satisfaction is no longer necessarily offered through the photographic activity or mastery over the machinery of photography itself. Instead one's cultural capital is communicated and affirmed through mastery of the social media through which the image is broadcast. As Murthy (2013, unpaginated) notes:

in a world where communities are not tightly integrated and our voice may feel weak, Tweets might be perceived by their authors as empowering. This is particularly felt if other Twitter users reply to these Tweets.

Celebrity Tweeters and their audiences can therefore 'feel their own power', communicate and reassure themselves of their social capital by creating selfies or by reTweeting or commenting upon them.

Equally Bourdieu also observes that photographic activity encourages 'communication with others' by 'enabling people to relive past moments together, or to show others the interest or affection that one has for them' (Bourdieu 1996, 14). The broadcast of celebrity group selfies via Twitter encourages a collective experience due to the image's function as a referent to the broader event surrounding the celebrity group selfie, both the taking of the image itself, but also its broader dissemination via various media platforms such as Twitter. As has previously been discussed, in reTweeting an image, audiences are deliberately contributing to the discourse about the image and it's reTweeting, they are vicariously participating in, and soliciting discourse about the event.

Bourdieu also claims that photographic activity "provides the satisfactions of prestige, in the form of technical prowess, or evidence of a personal achievement... or of ostentatious expenditure' (Bourdieu 1996, 14). Again this is applicable to celebrity group selfies and their reTweets. Here, the Tweeter presents an image of themselves, but borrows from the worth, or collective 'worths' of all the participants within the celebrity group selfie. Retweeting a celebrity group selfie offers a means of affirming one's place in an online, social hierarchy, garnering prestige amongst one's online peers, of demonstrating and/or increasing one's social and cultural capital, and in turn, one's economic value within the symbolic economy.

In conclusion, the celebrity group selfie has important functions both for stardom and fandom. It evidences the position of a celebrity amongst the society of other stars, and in which that celebrity may be trading up, or 'roughing it' with lower caste figures; whether a celebrity's status is enhanced or diminished by their company is decided largely by the 
reaction to the image, and its apparent appropriateness. The arbiters of this 'appropriateness' are apparently the audience, who chose to follow the stars and retweet their images, or ignore them; behind this choice, however, are the media gatekeepers of Twitter, who direct Twitter users to particular images, promote and sponsor accounts and stars, and make judgments as to who and who is not allowed into the firmament of the Twittersphere.

As audiences and fans increasingly experience celebrity lives and media events through social media platforms, the reTweeting, 'favouriting' or replying to a celebrity's message or photograph becomes both part of 'being a good fan', of showing loyalty to the star, and a way of taking part in the celebrity's performance and in their extended social life as well as being a means of demonstrating one's social capital and asserting one's own place within the symbolic economy. As the online extension of the 'star persona', these Tweets are the apparently unguarded 'off screen' thoughts and social interactions of the stars, into which the audience are invited to participate. Twitter therefore becomes the backstage extension of the media event, the personal view of the account holder, and the fan becomes an active and present participant in that (online) event. As such, the cumulative fandom of these fans, and their followers, and their followers' followers, becomes the measure of not just a celebrity's online reach (or value), but the appropriateness of their online presence and relevance, despite this reach being mediated by the orchestrations of traditional media outlets.

In asserting their belief in the celebrity of other stars, through the taking of group selfies, celebrities assert their social capital in both the celebrity community and the online community and in agreeing to be celebrities together, they demure to each other as mutual fans, recognising each other's status. If the delicate balance of online and celebrity capital is negotiated stars reinforce their celebrity through a selfie product which has a cumulative capital beyond that of the individual, increasing the star's reach, recognisability and value.

\section{References}

Baudelaire, C. (1980) 'The Modern Public and Photography' in Trachtenburg, A (ed) Classic Essays on Photography. Guilford: Leete's Island Books, 83-90

Bourdieu, P. (1996) Photography: A Middlebrow Art. Cambridge: Polity Press

Bright, S. (2005) Art Photography. London: Thames and Hudson

Bull, S. (2010) Photography. London: Routledge

Collings, B. (2014) '\#selfiecontrol: @CAZWELLnyc and the Role of the Ironic Selfie in Transmedia Celebrity Self-Promotion', Celebrity Studies, 5:4, 511-513

Davidson , R and Williams, A. (2014) Daily Mail "'One politely declines": Prince Charles Opts out of Joan Collins' Attempt to Mimic Oscars Selfie at the Prince's Trust Awards... with a Slightly Less Famous Crowd' [online] March 12. Available at http://www.dailymail.co.uk/tvshowbiz/article-2579252/Princes-Trust-Joan-Collinsmimics-famous-Oscars-selfie.html Accessed December 10, 2014 
Dent, G. (2011) How to Leave Twitter: My Time as Queen of the Universe and Why This Must Stop. London: Faber and Faber

@ dudleycruse [online] March 13, 2014 https://twitter.com/dudleycruse/status/444027041839841280 Accessed December 10, 2014

Dyer, R. (1986) Heavenly Bodies: Film Stars and Society. London: Macmillan

Dyer, R. (2007) Stars. London: BFI

Fahy, C and Flint, H. (2014) 'The Epic Selfie that Broke Twitter: Ellen DeGeneres's Snap with Jennifer Lawrence, Bradley Cooper and Meryl Street gets ReTweeted by Millions.' Daily Mail [online] March 3. Available at http://www.dailymail.co.uk/tvshowbiz/article-2571848/Ellen-DeGeneres-wins-A-ListOscars-crowd-gentle-teasing-Liza-Minnelli-not-impressed-mistaken-maleimpersonator.html Accessed December 9, 2014.

Fiske, J. (1992) 'The Cultural Economy of Fandom', in Lewis, L. A. (ed), The Adoring Audience: Fan Culture and Popular Media. London: Routledge

Gundle, S. (2009) Glamour: A History. Oxford: Oxford University Press

Hamilton K and Hewer, P. (2010). 'Tribal Mattering Spaces: Social Networking Sites, Celebrity Affiliations, and Tribal Innovations.' Journal of Marketing Management. $6: 3-4,271-289$

@ HClaytonWright [online] March 2, 2014 https://twitter.com/HClaytonWright/status/440325513446719489 Accessed December 11,2014

@juicy_john [online] March 13, 2014 https://twitter.com/juicy_john/status/444014080605822977 Accessed December 10, 2014

Lueck, J.A. (2012) 'Friend-Zone with Benefits: The Parasocial Advertising of Kim Kardashian’, Journal Of Marketing Communications. 1-19

Moseley, R. (2002) Growing Up with Audrey Hepburn: Text, Audience, Resonance. Manchester: Manchester University Press

Murthy D. (2013) Twitter: Social Communication in the Twitter Age. Cambridge: Polity Press

Rojek, C. (2001) Celebrity. London: Reaktion

Schickel, R. (1985) Intimate Strangers: The Culture of Celebrity. Garden City, New York: Doubleday 
Selby, J. (2014) 'Joan Collins Selfie: Actress Makes Cringeworthy Attempt to Copy DeGeneres Selfie as Prince Charles Dodges Photographic Bullet' Independent [online] March 13. Available at http://www.independent.co.uk/news/people/news/joan-collins-selfie-actress-makescringeworthy-attempt-to-copy-ellen-degeneres-oscars-selfie-as-prince-charles-dodgesphotographic-bullet-9189164.html Accessed December 10, 2014

Sky News 'Oscars Celebrity Selfie Breaks Retweet Record' [online] March 4, 2014. Available at http://news.sky.com/story/1219960/oscars-celebrity-selfie-breaks-retweetrecord.html Accessed December 10, 2014

Smith, P. Prepared for Death: Memorial Photography and Contemporary Funerary Custom. Talk given as part of the Faculty of Arts and Humanities Interdisciplinary Seminar Series: 'Death' at University of East Anglia.

Sontag, S. (1977) On Photography. London: Penguin

@ TheEllenShow [online] March 2, 2014. https://twitter.com/TheEllenShow/status/440322224407314432 Accessed December 10,2014

Wallop, H. (2014) 'Oscars 2014: The Most famous 'Selfie' in the World (Sorry Liza)' Telegraph [online] March 3. Available at http://www.telegraph.co.uk/culture/film/oscars/10674655/Oscars-2014-The-most-famousselfie-in-the-world-sorry-Liza.html Accessed December 10, 2014.

Dr Ellen Wright is the Vice Chancellor's 2020 Lecturer in Cinema and Television History at De Montfort University, Leicester. She has previously taught film studies, media studies and photographic theory and specialises in the study of leisure industries, consumer culture and broader social contexts surrounding Hollywood cinema in the early, to mid-twentieth century. She recently completed her PhD thesis 'More Than Pin-Up Lines: Public Femininity and the Reception of Hollywood Glamour in Second World War Britain' at the University of East Anglia. She has spoken publically upon film noir, burlesque and feminism, pin-up, wartime advertising and female consumption, female film audiences and the femme fatale. Amongst other academic publications, she has written 'Glamorous Bait for an Amorous Killer!: How Audiences Were Lured By Lucille' for Frames cinema journal, co-written 'Betty Grable: An American Icon in Wartime Britain' for The Historical Journal of Film, Radio and Television and written a chapter on feminine performance in Gentlemen Prefer Blondes for the forthcoming edited collection Howard Hawks: New Perspectives.

Email: ellen.wright@dmu.ac.uk 